\title{
CURRICULUM AS CONVERSATION: VULNERABILITY, VIOLENCE, AND PEDAGOGY IN PRISON
}

\author{
Aislinn O'Donnell
}

Mary Immaculate College

University of Limerick

Aвstract. It is difficult to respond creatively to humiliation, affliction, degradation, or shame, just as it is difficult to respond creatively to the experience of undergoing or inflicting violence. In this article Aislinn O'Donnell argues that if we are to think about how to address gun violence - including mass shootings - in schools, then we need to talk about violence inside and outside schools. Honest, and even difficult, conversations about violence and vulnerability can take place in schools, and there are ways of working with curricula and student voice that can allow for this. If pedagogy is to play a role in reorienting responses to violence and vulnerability, discussion of equivocal and ambivalent responses to corporeal vulnerability, and of histories and genealogies of violence, must be invited. We need to acknowledge that we do not have, and we may well never have, a world without violence. Drawing upon the experience of teaching philosophy in nontraditional learning environments, including prison, O'Donnell argues for an approach to pedagogy and curricula that invites difficult conversations about the complexity of violence.

\section{On Violence, Visible and Invisible}

Writing about the tragedy of school shootings is difficult; the attempt to understand can be interpreted as an attempt at justification, exculpation, or even legitimation. However, not to attempt to understand risks constituting school shooters as "exceptions" or "anomalies" and risks ignoring the difficult experiences inside and outside education that school shooters share with other young people. Acts like school shootings do not occur ex nihilo. They have a context and are motivated by reasons and conditions, however problematic these are. The act of (attempted) mass murder tends not to be spontaneous but rather is ruminated upon and planned in detail. To conceptualize such acts of violence as anomalous or psychopathic, to try to locate a generic profile of the school shooter, or to focus on singular causal processes risks ignoring the difficult insights that might be born of descriptions and analyses that are more sensitive to context, history, institutions, individual lives, and stories. Such insights can help to illuminate not only what brought someone to kill in this way, but also what has happened to bring someone to feel that he or she cannot bear to continue with a life as it has been, such that the conclusion is reached that what is now required is the systematic murder of others, and even one's own suicide.

It is essential to acknowledge the grief and loss suffered by the families and friends of victims of mass murder in school, but the overwhelming nature of such experiences, coupled with the intense media scrutiny that follows such events, can mean that insufficient attention is directed to instances of less visible violence experienced and witnessed by children in everyday life. As a result, other acts of violence and suffering risk becoming "normalized" or "naturalized." In the case of school shootings, violence is conceived of, performed, and expressed as spectacle 
and exception. Other practices and experiences of violence - be they physical, structural, and psychological, manifested in degradation, humiliation, exploitation, bullying, poverty, and discrimination - can end up being conceptualized as somehow different in kind, and even somewhat lesser, in order to underline the particular horror of school shootings and the lives lost and damaged. I want to argue against conceiving certain acts of violence as different in kind, or exceptional, which is not to deny that different forms of violence are distinct, or that some are irrevocable. If we adopt the premise that acts such as school shootings are anomalous or incomprehensible, this mystifies these acts and undermines the task of understanding how "minor" instances of everyday violence and broader cultures of violence, including state violence, can contribute to more devastating acts of violence. Accumulated minor infractions - in particular those that provoke shame and humiliation, as Amy Shuffelton argues ${ }^{1}$ - can make the lives of children and young people intolerable. Seeking to redress those wrongs should be done for its own sake, and not simply because this will diminish the likelihood of school shootings. Care must be taken not to focus only on the kind of violence that commands attention through spectacular manifestations. Even if better understanding does not yield the capacity to predict who will commit such acts, it can support change to conditions and contexts that contribute to the experience and perpetration of violence in young people's lives.

But which kinds of violence are seen as comprehensible, and even acceptable? Why are certain acts of violence that result in the loss of the lives of children and young people, such as those committed in conflict, military aggression, or even localized gang violence, not seen as grounds for the kinds of mourning witnessed in the aftermath of school shootings? And what class and racial presuppositions about perpetrators does this reveal? Indeed, what opportunities for public grief and mourning exist to mark the lives lost within U.S. communities of color, communities that continue to remain statistically overrepresented in terms of death by homicide and imprisonment? I do not pose these difficult questions to diminish the tragedy of school shootings, but to try to heighten sensitivity to and awareness of the ways in which some instances of violence are seen as more tragic than others. This seems to suggest that human lives are weighted in different ways, and only some deaths are seen as worthy of mourning in the public domain. Strangers' responses, including empathic attunement and sensitivity to the grief and loss of parents, children, families, and communities in the aftermath of school shootings, can also unfortunately serve to reveal which lives are seen as more or less valuable, and which kinds of violence are viewed as more comprehensible,

1. Amy Shuffelton, "Consider Your Man Card Reissued: Masculine Honor and Gun Violence," in this issue.

AISLINN O'DONNELL is Lecturer in Philosophy of Education in the Department of Learning, Society, and Religious Education at Mary Immaculate College, University of Limerick, South Circular Rd, Limerick, Ireland; e-mail <aislinn.odonnell@mic.ul.ie>. Her primary areas of scholarship are philosophy of education, Spinoza and the Spinozist heritage, and contemporary European philosophy, in particular Gilles Deleuze and Félix Guattari. 
and even inevitable. Although in this article I do not explicitly address important questions such as why "race" and ethnicity tend not to be invoked in the case of rampage shootings, the values of societies can be understood through the ways that they respond to different acts of violence, depending on the perpetrator. Selective mourning raises the challenging question of how to talk about violence when violence is everywhere and hierarchies of victims dictate which forms of violence are seen as justifiable or explicable. Reflecting upon how certain acts of violence and certain victims are barely visible helps us recognize what kinds of violence are seen as quasi-natural and thus tolerable. Although the focus here is on school shootings, I want to acknowledge, and not diminish, other forms of violence.

My suggestion is that if we are to think about how to address gun violence in schools, we need to talk about violence inside and outside schools. The complex terrain of violence can be addressed through curricular exploration and creative pedagogies. For example, one could interrogate those imaginaries that privilege whiteness, material wealth, symbolic power, masculinity, and even "normality." Renewed honest conversations and reimagined curricula would ask how we can respond to, and talk about, violence in the broader lived context of students. These conversations and curricula would find ways of including the voices of those who are pushed outside and beyond political consideration. The ways in which people respond to perpetrators as well as victims of violence make the boundaries of political communities visible.

Of course, experiences of systemic injustice, powerlessness, and marginalization do not necessarily cause violence. Moreover, as has been pointed out by a number of commentators, mass school shootings, and indeed most rampage shootings, are not committed by young black men and boys but by white men and boys. To be a young black male in the United States means that one is at risk of being murdered by those who view the fact of your existence as a threat, and that one is constantly exposed to the ways in which such murders are both de facto and de jure too often seen as justified and justifiable. This also raises important questions that I cannot address fully here, such as why is it the case that boys and young men of color do not seek revenge through rampage shootings, even though compared with their white peers, they may undergo more acute marginalization and discrimination?

The possibility that one might be murdered simply for existing is not something that school shooters face, but, paradoxical as it may seem, it may be that discrimination and injustice on the basis of what one is, through being categorized as a member of a group that is different from the majoritarian norm, can offer access to a set of collective understandings of injustice and dispossession. Being seen as a specimen of a group - for what rather than who one is - raises its own painful difficulties, as Frantz Fanon and others have elaborated. ${ }^{2}$ Yet Michael Kimmel and Matthew Mahler write that subordinate groups "can tap into a

2. See, for example, Frantz Fanon, Black Skin, White Masks, trans. Charles Lamm Markmann (New York: Grove Press, 1967); W. E. B. Du Bois, The Souls of Black Folk (1903; repr. Boston: Bedford Books, 1920); and Ralph Ellison, Invisible Man (New York: Random House, 1952). 
collective narrative repertoire of resistance. They can collectivize their anguish so that the personally painful may be subsumed into readily available political rhetorics." 3 To be marginalized or excluded on the basis of who one is, when one may have expected to belong to the dominant subject position, can precipitate a particular kind of pain and humiliation because of the prior expectation of belonging and the cruelty with which one may be excluded. This is not to buy into those discourses that mourn the loss of male, class, or white privilege, but rather to understand how thwarted expectations can engender disappointment, and even violence, when privilege is not enjoyed in the life of someone who expected it. This does not mean that school shooters are simply narcissists. Many were bullied and excluded, whereas others were not but perhaps did not "fit." "White boys who are bullied are supposed to be real men, supposed to be able to embody independence, invulnerability and manly stoicism." 4 Those responsible for the Montréal Massacre and Columbine "came to the conclusion that they deserved to use violence and to take lives, as a way to reclaim their place within a social hierarchy that they thought diminished their privilege. ${ }^{\prime 5}$

People who are unjustly treated can find ways of building critical modes of solidarity, but it seems as though these boys and young men had no access to, or interest in, the formation of collective imaginaries that enable complex and creative responses to a lack of belonging. To be different "from" presupposes a normative standard that categorizes and sorts people into positions that differ from that norm. The pain of shame and humiliation of those who fail to accede to that norm, when they might expect to or be expected to, differs from the pain suffered due to structural exclusions and inequalities. Shame, humiliation, and vulnerability strike at the heart of the self, given the images of sovereignty and stoicism that define male imaginaries and also the dominant philosophical and political imaginaries of the West. ${ }^{6}$ The exertion of force provides a powerful mechanism to regain face and demand respect. The feature common to most school shootings is that they are committed by young, white, suburban, middle- to upper-class males who have experienced themselves, whether or not it is the case, as having been humiliated or ostracized within an educational setting.

If we allow that we ought to remain cognizant and sensitive to the many forms of violence in the world, and the patterns of privilege, visibility, and exploitation that shape different responses to exclusion, what can this contribute to our understanding of the tragedy of mass shootings in educational spaces? In the next

3. Michael Kimmel and Matthew Mahler, "Adolescent Masculinity, Homophobia, and Violence: Random School Shootings, 1982-2001," American Behavioral Scientist 46, no. 10 (2003): 1453.

4. Ibid.

5. Karen Tonso, "Violent Masculinities as Tropes for School Shooters: The Montréal Massacre, the Columbine Attack, and Rethinking Schools," American Behavioral Scientist 52, no. 9 (2009): 1270 (emphasis in original).

6. In "Consider Your Man Card Reissued," Shuffelton explores elements of this in the relation of shame and honor. 
section, I examine some of the literature that develops the "profile" of the school shooter and the dominant imaginaries of schooling and education today in order to consider the complex relationship between violence and vulnerability.

\section{The School and the "Securitization" of Education}

Current educational and school imaginaries, by which I mean the generation of images of education, students, and schools that are both representational and creative, increasingly share certain features. These include (1) privileging discourses of control; (2) the prioritization of behavioral management strategies as a solution to perceived psychological and social problems; (3) increased readiness to suspend and expel students for minor infractions; (4) punitive responses from an early age that include the criminalization of children; (5) fortification of the site of the school; and (6) practices of risk management that can increase risk. I describe this as the "securitization" of education. Such imaginaries reveal an unwillingness to explore more deeply what school shootings reveal about school and societal cultures, such as vulnerability, power, fear, or the sense of exclusion described by perpetrators of school shootings. Values transmitted to students involve images of mastery, control, flourishing, sovereignty, competition, and autonomy. A more antiheroic pedagogy might permit less heightened expectations for one's own life, decency toward others, and a gentler, even humorous, response to the human condition.

Such antiheroic principles are unlikely in the fortified zones that some schools have become. Even Michel Foucault might have been surprised at the direct mirroring of practices from prisons. Schools are increasingly constructed as spaces for micro control in the United States and elsewhere. "Schools, these days," write Ivan Watts and Nirmala Erevelles, "look like prisons, complete with prison officers, security cameras, metal detectors, and the institution of dress codes that demand conformity." 7 This increase in micro levels of control is not without consequence. Measures to prevent violence in school and to ensure safety can create environments of anxiety and intimidation. They are symptomatic of societies that are increasingly intolerant of certain kinds of risk, and following much contemporary educational policy, they tend to promote generic and technical "what works" approaches to problems, showing little sensitivity to the need for singular judgments.

Dianne Gereluk, Kent Donlevy, and Merlin Thompson demonstrate the importance of developing appropriate, measured, specific, and situated approaches to managing risk and responding to threat. ${ }^{8}$ Benevolent efforts to ensure the well-being and safety of young people risk excessive vigilance if they involve intolerance of even the most remote risks. Such measures of control can result

7. Ivan Watts and Nirmala Erevelles, "These Deadly Times: Reconceptualizing School Violence by Using Critical Race Theory and Disability Studies," American Educational Research Journal 41, no. 2 (2004): 271.

8. Dianne T. Gereluk, J. Kent Donlevy, and Merlin B. Thompson, "Normative Considerations in the Aftermath of Gun Violence in Schools," in this issue. 
in quasi-coercive forms of risk management that corrode school life. When protocols deployed without judgment are combined with physical reminders of the threat of violence, this risks making schools feel like sites of potential crisis in a permanent state of emergency. This is likely to do significant damage to students' sense of trust in each other and in other humans. It precludes the potential for creating "unmanageable" and "unpredictable" spaces for students where they can have voice, express themselves, and dissent. Rather than a laboratory for experimentation with ideas and experiences, the educational imaginary of schools ends up resembling a clinical and sanitized laboratory combined with the security apparatus of the prison, inscribing powerlessness and anxiety into the body politic of the school.

Watts and Erevelles describe some of the practices of zero-tolerance within schooling that criminalize children for ordinary disagreements, that label and pathologize children, and that silence students through the implementation of codes and protocols, without listening to their stories or their reasons. They also note the growth industry of "pathologization of children of poverty" that has become "a lucrative business whereby professionals interact with these children armed with a battery of tests, boot camps, and other behavioral-management programs that are more profitable to the professionals than beneficial or humanizing for their clients." ${ }^{\prime 9}$ Such practices do not simply exemplify what Foucault calls "governmentality," but they are motivated by profit. ${ }^{10}$ Relationships with risk and perception of threat more broadly have an impact on how schools function. Gereluk and colleagues argue that what is required is the ability to judge in light of the specificity of the situation with which one is confronted, and with the safety and well-being of the child and other members of the school community in mind. ${ }^{11}$ It is essential to require that the educational value of any initiatives that we may wish to introduce be shown. Such approaches could support a more critical examination of how schools respond to perceived risk.

Yet even as schools are increasingly constituted as potential stages for certain kinds of violence, other kinds of violence remain relatively invisible. Both schools and society more broadly offer cultural scripts that privilege certain kinds of responses to violence, which depend on the perceived identity of the perpetrator. Given that the risk of death in a school shooting is so much lower than other risks young people face, why are schools increasingly fortified zones? Watts and Erevelles argue that "policies to prevent school violence become the most effective way of disciplining, regulating and controlling students and teaching them their place within a racial and class hierarchy."12

9. Watts and Erevelles, "These Deadly Times," 291.

10. Michel Foucault, Discipline and Punish: The Birth of the Prison (New York: Random House, 1975).

11. Gereluk, Donlevy, and Thompson, "Normative Considerations in the Aftermath of Gun Violence in Schools."

12. Watts and Erevelles, "These Deadly Times," 292. 
Studies that concentrate exclusively on those psychological variables that describe the cognitive and affective deficits of the shooter can result in decontextualization of the act. They privilege abstract typologies because they do not interrogate the conditions of the lived experience of these students, and other students and staff. In school shootings, as Harvey Shapiro explains, media coverage and official reports have tended to focus on the exceptional and anomalous nature of the shooter. ${ }^{13}$ The opportunity to develop, for example, an intersectionalist analysis has tended to be passed over in favor of pathologization of the individual or suggestions to improve resilience. Mia Consalvo notes that in the case of Columbine and other school shootings, "school culture, whiteness, and the hierarchical structure of masculinities were let off the hook far too easily, and instead media outlets focused on the more sensational elements: video games, guns, and the internet."14 As Kimmel and Mahler point out, this tends not to be the case when a member of another ethnic group engages in an act of violence. ${ }^{15}$ When Seung-Hui Cho, one of the few exceptions to the white male profile in school shootings, murdered thirty-two people at Virginia Tech, the Korean community in the United States expressed shame, the South Korean government apologized, and there was fear of retributory attacks on the Korean-American community, yet there has never been any sense that male Caucasians, as a generic category, should bear responsibility for acts of atrocity committed by members of their own "ethnic group." Arguably because they are predominantly white and middle class, school shooters are not racialized, nor are their actions attributed to shared group characteristics, as they often are in other cases of violence. Indeed, many studies in the psychological and criminological literature, including those that try to develop an integrated and nuanced response to school shootings, fail to sufficiently examine and explore the relationship between the school imaginaries, political imaginaries, and masculine imaginaries constitutive of human subjectivities.

We have already looked at one response to risk, when examining the fortification and securitization of the school environment. With respect to the specific issue of school shootings, the FBI's proposal for threat assessment includes personality traits, family dynamics, school dynamics, and social dynamics. Yet, the difficulty with profiling school shooters is acknowledged because so many young people share those characteristics that could be used to identify school shooters. The implications of profiling, based on narrow cultural-psychological characteristics that are decontextualized and depoliticized, are spelled out by Arun Kundnani. ${ }^{16}$ He shows that the profiling of Muslims in the United States

13. Harvey Shapiro, "When the Exception Is the Rule: School Shootings, Bare Life, and the Sovereign Self," in this issue.

14. Mia Consalvo, "The Monsters Next Door: Media Constructions of Boys and Masculinity," Feminist Media Studies 3, no.1 (2003): 40.

15. Kimmel and Mahler, "Adolescent Masculinity, Homophobia, and Violence," 1443.

16. Arun Kundnani, The Muslims Are Coming! Islamophobia, Extremism, and the Domestic War on Terror (London: Verso, 2014). 
and the United Kingdom has meant that spaces for political dissent and reasonable questioning of state violence perpetrated by the US and the UK in the "war on terror" have been closed down. There are, of course, differences here from the case of school shooters in that it is recognized in the case of school shootings that it is unwise and unhelpful to profile, given the difficulties of identifying those individuals who constitute a real threat, whereas the opposite approach appears to be at play in the attempts to locate those who might potentially become "Islamic fundamentalists" or "radicalized" elements within Muslim communities. Kundnani draws on science fiction novelist Philip K. Dick's term "thought-crime" to describe this process of trying to isolate the variables that might lead someone to become radicalized. ${ }^{17}$ Part of the problem with this perspective is that it fails to look at the broader context. Indeed, it shows the considerable risk of developing decontextualized and ahistorical approaches that either focus on individuals in abstraction from the world, or, in the case of schooling, that seek to manage specific environments through a logic of "securitocracy," which in turn creates the conditions for the very phenomena of violence that these approaches were seeking to avoid. The real question for prevention is how to respond to, and understand, violence.

\section{Varieties of Degradation: The Difference between Vulnerability AND AfFliction}

I have indicated some of the (un)intended consequences of making schools more secure, closed institutions. This section makes some philosophical observations about the relationship between violence, affliction, and vulnerability in order to help us to think about different kinds of responses that are more attuned to context and more historically and contextually grounded. One response has been to acknowledge our mutual vulnerability as a way through the impasse of violence. There are, however, problems with responses that seek to develop an antiviolent ethics and politics of vulnerability. It is not clear that the mere awareness of vulnerability, interdependence, and finitude translates into an ethics and politics of vulnerability. I caution against overoptimism that such insights will lead to a more open and sensitive ethics and politics. Ethics and politics that begin with vulnerability, rather than autonomy understood as sovereignty or self-mastery, ignore predation upon perceived weakness, overemphasizing sensitivity or compassion. Yet, pedagogical work in schools and educational institutions can affect and transform common responses to vulnerability and affliction in that pedagogies of violence and vulnerability may allow for a creative movement from the experience or witnessing of vulnerability to less destructive relationships.

One effort to think through this vexed question of violence is offered by Judith Butler in Precarious Life. She writes of the ways in which humans might respond to vulnerability other than through counterattack, pointing out the inconsistency of responses to acts of violence; depending on who the perpetrators and victims are, violent acts and deaths are read differently. Asking "Who counts as human? 
Whose lives count as lives? And finally, What makes for a grievable life?," Butler's account is a sensitive one, beginning with the bare exposure of humans to one another. ${ }^{18}$ She wants to reject the quest for security and control that has come to mark our present era. We humans are undone by one another, but the experience of undergoing violence can push us to revert to a first-person narrative that refuses engagement with the complexity of the human condition, or to interrogate imaginaries premised upon mastery and sovereignty and, in the process, consider our own complicity in the perpetuation of certain kinds of violence. She does not believe that to try to understand or explain serves to exculpate, but thinks that if we do not do so, "we shall fail to take collective responsibility for a thorough understanding of the history that brings us to this juncture. We shall therefore deprive ourselves of the very critical and historical resources we need to imagine and practice another future, one that will move beyond the current cycle of revenge. ${ }^{\prime 19}$ Her approach, concerned with developing creative rather than reactive responses to undergoing violence, makes the argument for the necessity of challenging responses that seek to eliminate vulnerability and secure mastery. In many respects, her motivation and analysis is correct and praiseworthy; however, it can be difficult if one is subjected to violence, especially as a child or adolescent, to find the spaciousness and generosity required for a different response to shame. Arguably, Butler fails to take into account the depth of investments in power, sovereignty, or mastery, often fueled by inequality, which means that encountering vulnerability may for some afford the pleasure of domination and the opportunity to distinguish oneself and reassert one's identity. Experiences of vulnerability, dispossession, and violence are not equivalent and some can be deeply corrosive.

So while I am deeply sympathetic to this kind of ethics and politics, I am not convinced that merely experiencing, bearing witness to, or understanding the place of vulnerability and mutual dependence in the human condition generates more creative responses. This matters when we, as educators, decide how to navigate hierarchies of belonging in schools and educational institutions, and respond to the many forms of coercion, control, and violence in school life. Appealing to positive conceptions of humanity and developing social and emotional skills programs are both useful and laudable but may inadvertently preclude more honest and difficult conversations about violence in everyday life.

Many philosophers have written of the fraught move from the experience of vulnerability to practices of pedagogy that are transformative, without resorting to prescriptive norms. Martin Buber describes the difficulties of moral education and character education in Between Man and Man:

I try to explain to my pupils that envy is despicable, and at once I feel the secret resistance of those who are poorer than their comrades. I try to explain that it is wicked to bully the weak, and at once I see a suppressed smile on the lips of the strong. I try to explain that lying destroys

18. Judith Butler, Precarious Life: The Powers of Mourning and Violence (London: Verso, 2004), 20 (emphasis in original).

19. Ibid., 10. 
life, and something frightful happens: the worst habitual liar in the class produces a brilliant essay on the destructive power of lying. I have made that fatal mistake of giving instruction in ethics, and what I said is accepted as current coin of knowledge; nothing of it is transformed into character building substance. ${ }^{20}$

It is difficult to respond creatively to humiliation, affliction, degradation, or shame, just as it is difficult to respond creatively to the experience of undergoing or inflicting violence. It would be fairly straightforward were such matters simply caused by psychological dispositions, traits, or learned behaviors that could be modified with targeted interventions, but usually far more entangled forces, histories, images, and relations are at play.

In "The Iliad, or the Poem of Force," Simone Weil defined force as "that $x$ that turns anybody who is subjected to it into a thing." ${ }^{21}$ She thinks that the quest for power, prestige, and wealth, exemplified in contemporary capitalism, fortifies and legitimates zero-sum, asymmetrical relations that inevitably diminish the dignity of some. She writes, "prestige, from which force derives at least three-quarters of its strength, rests principally upon that marvelous indifference that the strong feel toward the weak, an indifference so contagious that it infects the very people who are objects of it." 22 This analysis of power, force, violence, pity, and affliction deepens our understanding of the desire for revenge, or even lack of gratitude from those given support, because just as vulnerability does not necessarily inspire understanding, charity and compassion may provoke reactions of anger or rejection on the part of the beneficiary. The suffering caused by hierarchical relations that institute inequality, and the complex imbrication of pity, disgust, and brutality in the presence of perceived weakness, create a tangle of conflicted reactions. As Butler writes, we falter "between the fear of undergoing violence and the fear of inflicting violence." 23

In Gravity and Grace, an edited compilation from her notebooks, Weil writes, "Too great affliction places a human being beneath pity: it arouses disgust, horror, and scorn. Pity goes down to a certain level but not below it." 24 Those who are most marginalized and most afflicted - for example, drug users or the homeless - may well be received with contempt instead of compassion. A situation that is too hard for us to bear eventually degrades us, but we react to this in different ways. In this sense, affliction is not the same as physical suffering; it involves social degradation. Weil writes,

Affliction is anonymous before all things; it deprives its victims of their personality and makes them into things. It is indifferent; and it is the coldness of this indifference - a metallic

20. Martin Buber, Between Man and Man (London: Kegan Paul, 1947), 124.

21. Simone Weil, "The Iliad, or the Poem of Force," Chicago Review 18, no. 2 (1965): 6.

22. Ibid., 18.

23. Butler, Precarious Life, 137.

24. Simone Weil, Gravity and Grace (London: Routledge, 2002), 3. 
coldness - that freezes all those it touches right to the depths of their souls. They will never find warmth again. They will never believe any more that they are anyone. ${ }^{25}$

Being in the opposite direction to nature, the sympathy of the strong for the weak is against nature, and that pain of exclusion is intensified, she thinks, because of the human passion to belong. For Weil, the response must be creative attention, a "supernatural" act, which can transform into love the commonplace reaction of contempt in the face of weakness and vulnerability.

Ann Murphy's position is even more nuanced as she outlines the equivocity, ambivalence, and ambiguity of vulnerability. Rather than hoping for an ethics of creative attention, like Weil, or an ethics of vulnerability that understands both our susceptibility to harm and our capacity for joy in our shared corporeal embodiment and finitude, Murphy writes "the normative bent of the vulnerable body remains powerfully ambiguous; in and of its own right, it neither sanctions nor forbids violence." ${ }^{26}$ Efforts to develop a productive appreciation of vulnerability may not lead to an "attempt to respect the vulnerability of others." Instead, "a sense of one's own dispossession, availability to others, and vulnerability may incite violence just as readily as it does empathy, care, or tolerance." 27 The experiences of vulnerability and dispossession lack prescriptive force in the sense that no ethics or politics necessarily follow from such experiences; the words Seung-Hui Cho and Pekka-Eric Auvinen used to explain their deeds demonstrate this. Statements of these school shooters show how finding strategies to dehumanize others involves for some, like Dylan Klebold and Eric Harris, elevating oneself, whereas others, like Cho, identify with a community of the dispossessed. Both approaches facilitate the act of killing.

Sharon Todd offers a perspective that resonates with that of Murphy when she questions the idea that utopic cosmopolitan educational ideals can be developed in response to the perennial problem of violence. Instead, we are asked to face "how things are." 28 This image of humanity in education does not seek to occlude the violence, antagonism, and conflict endemic to human relations. To face humanity requires facing the person in all his or her complexity while also acknowledging our own capacity for violence.

\section{Creative Responses: Conversations and Curricula that Face Humanity}

Honest conversations about violence and vulnerability can take place in schools, and there are ways of working with curricula and student voices that might allow for this. If pedagogy is to play a role in reorienting responses to violence and vulnerability, discussion of equivocal and ambivalent responses to corporeal

25. Simone Weil, Waiting for God (New York: G. P. Putnam's Sons, 1951), 73.

26. Ann Murphy, Violence and the Philosophical Imaginary (Albany: State University of New York Press, 2012), 66.

27. Ibid., 68

28. Sharon Todd, Toward an Imperfect Education: Facing Humanity, Rethinking Cosmopolitanism (Boulder, CO: Paradigm, 2008). 
vulnerability, and of histories and genealogies of violence, must be invited. We need to acknowledge that we do not have, and we may well never have, a world without violence.

Although here I write in part from my experience of the site of the prison, I am aware that it is one thing to develop relations of trust within a prison, where the lines of power are clearly drawn and the identity of the prisoner already constituted and criminalized, and another to try to build relations of trust in schools that look like prisons. In the latter case, children and young people can ask with good reason why they are being constituted as threats and can resist the constant reminders of potential aggression and violence visible in the architecture, including armed presence in the environment. To have the kinds of conversations I am suggesting, trust is essential, but to construct school environments as militarized zones militates against this.

Over the past decade, I have developed a number of projects to introduce and teach philosophy to a range of students. Some are at postgraduate level, others struggle with literacy, and nearly all have a history of imprisonment. The classes have taken place in a high security prison; in the kitchens of two organizations that work with people on probation or day release from the prison, including people who are homeless; and in an organization that works with people who are HIV positive and/or (former) drug users, with people in recovery from drug use, as well as with women who have experienced domestic violence. The classes take the form of philosophical conversations and move between story, analysis, and texts. Students can engage further if they choose to do so. In many of these classes, we have discussed the question of violence. When codeveloping a curriculum with men and women who had been in prison, the first Socratic question suggested by one woman, and agreed to by the group, was "What is violence?" Discussions about violence can be embedded in a more expansive and exploratory curricular vision. A philosophical-pedagogical approach that is grounded in the arts, social sciences, and humanities is useful if we wish to talk about violence through the curriculum in a way that is more suggestive than didactic. If there is to be a bridge between the experience of vulnerability, including vulnerability experienced through violence, and those ethical and political approaches that wish to build positively and creatively on that experience, a pedagogy that can move subtly between different aspects of experience and knowledge is required. I do not mean by this direct instruction about violence, although such an approach may have its place in storytelling and in developing knowledge. I agree with Martin Buber when he says that any attempt to directly form character will be resisted. Indirect pedagogies that emerge from conversations within those eclectic and diverse proto-public spaces that are school classrooms may be of more benefit.

For some in my classes, to be a man meant that violence was inescapable, not because of some desire to inflict violence, but because of the constant threat of violence and the fear of assault, particularly in coercive institutional settings or conflict-ridden local environments. Sometimes, the dominant experience throughout childhood involved witnessing or being subjected to violence, so one learned 
to respond preemptively. Oddly, this experience of vulnerability can lead to inflicting violence. The purpose of discussion is not to ask students to disclose their own stories as in a therapeutic session, but to rather reflect upon and analyze experiences in order to better understand the human condition, the role that violence and antagonism play in human lives, and why this is the case. Monolithic or moralizing explanations of violence are not helpful if they occlude the many forms of violence encountered in life and the capacity that each one of us has for violence. The context of the classroom allows for the discussion of concepts and ideas that extend beyond an individual's experience or actions, refusing the framing of violence through those narrowly psychological approaches that suspend the brutal nature of our common world.

Some "ordinary prisoners" in my classes speak and write of the inevitability of violence if one is a man and of the need to show one's capacity for violence. The institutional structures of the prison, in their view, silence those who try to speak truthfully and honestly, and reward violent action and reaction. They speak of the impossible silence of witnessing violence and being unable to comfort others who may be needlessly fearful, while voicing resistance to the idea that to be a man is to desire violence. Rather its expression and manifestation often serve the purposes of avoiding predation and preserving the self. Although some lived in fear of retributive violence, they remarked upon how difficult it is to speak of such fears or their own vulnerabilities among male peers. I do not wish to naïvely suggest that engaging in philosophical reflection necessarily allows one to escape the cold circular logic of force. Life is more complex than that, and the question of violence tends to be a social affair rather than a disposition of the individual. In conversation with an Irish senior barrister who said aloud, "I have never understood why those who have suffered from violence, go on to inflict it on others," I thought of the words of one man in response to his own violence, "It is all I know." And, looking at our world, there is violence everywhere.

To think more broadly about how one might talk about violence within a curriculum, it may be useful to think about how discussions might be "depersonalized" and decentered in such a way that they allow for exploration, reflection, analysis, description, and learning about the subject matter without locating and identifying particular individuals within the class as in need of edification. This kind of permeated approach cannot be forced or artificial but must remain educative in order to allow "breathing spaces" for students. Principles underpinning the ethic of the classroom discussion need to be agreed upon. The hierarchies of the prison and the forms of social exclusion experienced by men from working-class neighborhoods provide a context that can help us to understand the difficulties of navigating the inequalities and vulnerabilities of school environments. Although our sessions sometimes involve elements of personal disclosure, as is often the case with philosophy, this is woven into the broader substance of the conversation focused on understanding the nature of the topic. Creating a sense of intimate distance from the topic invites forms of disagreement and a willingness to engage critically and imaginatively with the perspectives of others on cognitive and affective levels, including coming to understand the complex genesis of a set of values 
and ideas that may have become naturalized in certain settings, such as the constitutional right to bear firearms or "stand your ground."

In the context of the United States, this could involve exploring the history of the emergence of the Second Amendment; the story of colonialism, racism, enslavement, genocide, occupation, and revolution; and the relationship between life then and life today. It could involve considering what is meant by "rights" and the correlative set of duties or responsibilities that could correspond to such rights today. It might entail looking at fundamental presuppositions about security, life, and bodily integrity, and thinking about the ways in which the "right to life" is interpreted. What is important is the creation of a space that allows for difficult forms of dissent and disagreement, that invites storytelling and observation, and that asks that all participants try to think critically, imaginatively, and with care about their own positions, remaining open to other worldviews and different perspectives while having the integrity and courage to disagree and the ability to explain why. This is different from a moralizing space that seeks to instruct young people about right and wrong, just as it is different from a therapeutic space that sees the origins of violence solely in the psyche rather than as informed and inflected by broader cultural, social, or economic conditions. An exploration of the human condition through the philosophy of Thomas Hobbes, Jean-Jacques Rousseau, or Hannah Arendt allows students to explore their own experiences and tacit assumptions about what it means to be human, our mutual vulnerability, and the nature of human interdependence or power.

This is education rather than targeted interventions designed to "treat" or even to change students. Classes are oriented and directed by the questions raised by my students and by myself. In the case of political prisoners, sometimes we speak about political violence. Those conversations have forced me to examine the selective nature of condemnations of violence (my own included) and our complicity as citizens, for example, in permitting the perpetuation of (state) violence through our silence. We might contemplate honestly the idea of pacifism, including how one can respond to those extreme situations where violence is no longer viewed as a tool, but is instead the only response available, such as Simone Weil's example of the need to use force in order to defend another human being if nonviolence will be less effective, though she also says we must strive for effective nonviolence. ${ }^{29}$ Weil writes of these complex human situations sensitively, wrestling with the obligation to let go of her absolute pacifism when confronting a world at war. At other times, we have talked about Antigone and her choice of the "Law of Nature" in burying her brother, Polyneices, instead of obeying the law of the state, embodied in the king and the father, Creon. Moving into the sphere of Greek tragedy allows the intimate distance that can allow difficult conversations to take place. When asked by some of my students about this hypothetical scenario, "Would I tell someone I love who had done something terrible that they should give themselves up to the police?" having witnessed the damage that prisons do,

29. Weil, Gravity and Grace, 85. 
I could no longer say that I would. This arguably immoral refusal revealed to me my feelings about imprisonment, feelings that are visceral, emerging through the experience of bearing witness, that is, by simply being and thinking in the site of the prison. At other times, we talked of Freud, trauma, and repression, or Kant and melancholia. These kinds of philosophical inquiry help us to think about difficult questions, such as what it means to murder, or if such an act, which would by definition require the recognition of another as subject, is even possible if one sees the "other" as another subject, as Gabriel Keehn and Deron Boyles ask. ${ }^{30}$ Such conversations invite all participants, including the teacher, to be changed.

If philosophy is understood as something we do because it helps us to live, then this interplay of deeply personal (whether spoken of or not) and philosophical stories can allow for a different kind of space, suspended temporarily from the cares of the everyday. Sufficient dispassion and the invitation to thinking, storytelling, and exploration are different from uninterrogated expressions of experience or the privileging of personal narrative encouraged in more therapeutic or morally prescriptive spaces. It is easy to moralize about violence when it is decontextualized into thought experiments, when acts are abstracted from their histories, or when generic images extrapolated from populations are privileged over the complex human being in a face-to-face relationship. This also means confronting the difficult fact that, despite rhetoric to the contrary, many institutional cultures, such as prisons and schools, support and reward violence. Indeed, these reflections by a man in one of my classes resonate with some of the descriptions of school environments:

The prison environment, no matter how new, shining, safe and secure, is like stepping back in time to maybe even as far back as the stone age. Survival of the fittest and macho culture rules. Kindness and weakness will be pounced upon. Appearance means much and the shy, weak, awkward and different will be picked upon and bullied. Unfortunately, violence is not the last weapon in your armory. It is the first and has to be used. Again, unfortunately violence is often the only thing some prisoners understand and respect. Indeed, some prison staff will only allow you to have or to do certain things after you have reacted violently, or if they know you are capable of this.

Don't try and beat the system. It is too big and powerful and you can't win. Work within the system, trying to keep as low a profile as possible, gaining your own personal victories wherever possible.

Know your environment. Learn the prison rules of what you are entitled to and not. Know the screws. Who is on duty, who is off duty, as this will have a bearing on your day. Also important is to know your fellow prisoners and their history, especially those in close proximity as this could save you a lot of trouble in the future.

Don't go out of your way to antagonize screws or indeed fellow prisoners. Don't make enemies unnecessarily as prison life is hard enough. To go out of your way, showing your contempt for screws or prison staff is foolish. They are your jailers, your keepers and they already don't like you, so don't compound the fact. Always have a smile on your face and that certain look that says you know a lot more than most.

30. Gabriel Keehn and Deron Boyles, "Sense, Nonsense, and Violence: Levinas and the Internal Logic of School Shootings," in this issue. 
Have full confidence in yourself and how you are serving your time to the best of your ability.

Treat all prisoners and screws with due respect and expect the same in return. ${ }^{31}$

Ordinary schooling practices and discourses might initially appear at a far remove from the prison. However, practices and cultures in schools can cultivate the conditions that promote violence and humiliation, as Bryan Warnick, Sang Hyun Kim, and Shannon Robinson argue. ${ }^{32}$ There may be too few opportunities for sensitive exploration of the central themes relating to the human condition. This is not the same as demanding that students expose their frailties, their vulnerabilities, and the stories of their lives. Students and teachers should be given time for honest discussion about why violence exists, the different ways in which violence can be understood, what it means to be this organism whose living, breathing body means it will always be vulnerable, or what is at play in violence, beyond efforts directed at character or moral education or the historical recitation of monumental events. Such discussions will probably not immediately transform endemic forms of inequality, but they may allow for the emergence of more delicate, subtle, and critical forms of discourse that extend beyond narrowly individualistic or psychological responses to the existence of violence. Although I appreciate well-intentioned initiatives meant to develop positive interventions, such as those that seek to transform school culture or develop young people's capacity for ethical living and emotional self-regulation, following Sharon Todd, I suggest that it could also be helpful to develop curricula that (1) face humanity; (2) foster the voice of children and young people; (3) puncture grandiose ambitions, favoring kinder and less heroic aspirations for human lives; (4) acknowledge that vulnerability often provokes contempt rather than inspiring compassion; and (5) create spaces that allow for difficult conversations about violence. ${ }^{33}$

Would this prevent school shootings? Perhaps not, but it might help to lessen the likelihood of these tragedies by making schools kinder, more honest, and more thoughtful environments that are interested in and encourage the voice of children and young people.

31. After having a conversation with one student, a man who said that he wanted to read Dostoevsky because all he knew was crime and punishment, I suggested that he knew more and the way he spoke of the techniques of the self resonated with the Stoics. He then sent me, through another prisoner, pages of his writings reflecting on "advice to a novice prisoner."

32. Bryan Warnick, Sang Hyun Kim, and Shannon Robinson, "Gun Violence and the Meaning of American Schools," in this issue.

33. Todd, Toward an Imperfect Education. 